\title{
Revised manuscript
}

Published in:

Colloids Surf B Biointerfaces. 2016 Nov 1;147:106-15.

doi: 10.1016/j.colsurfb.2016.07.054.

Epub 2016 Jul 28. 


\title{
Comparative analysis of new peptide conjugates of antitubercular drug candidates - model membrane and in vitro studies
}

\author{
Á. Ábrahám ${ }^{1 \#}$, Zs. Baranyai ${ }^{2 \#}$, G. Gyulai ${ }^{1}$, E. Pári ${ }^{1}$, K. Horváti $^{2}$, Sz. Bősze $^{2}$, É. Kiss ${ }^{1}{ }^{*}$ \\ 1 La boratory of Interfaces a nd Na nostructures, Institute of Che mistry, Eötvös Loránd University, Bu dapest 112, PO Box 32 , \\ H-1518 Buda pest, Hungary
}

2 MTA-ELTE Res earch Group of Peptide Chemistry, Budapest 112, POB 32, H-1518 Budapest, Hungary

*corresponding a uthor, E-mail: kisseva@chem.elte.hu

\# equal contribution a uthorship

\begin{abstract}
Novel peptide conjugates of two antitubercular drug candidates were synthesised and characterised using new tuftsin peptide derivatives (OT14) as carrier moiety. As antitubercular drug ca ndidates two pyridopyrimidine derivatives, TB803 (2allylamino-4-oxopyrido[1,2-a]pyrimidine-3-carbald ehyde) and TB820 (4-oxo-2-(pyrrolidin-1-yl)-pyrido[1,2-a]pyrimidin-3carba ldehyde) inhibiting vital enzyme of Mycobacterium tuberculosis were applied. Membrane affinity of the compounds TB803 and TB820 and their peptide conjugates was evaluated using experimental lipid mono- and bilayer models. Penetration ability was assessed tensiometrically from La ngmuir monolayer study a nd a pplying quartz crys tal microbalance for the supported lipid bilaye (SLB) system. Mi nimal inhibitory concentration (MIC) values remained in a similar micromolar range for both of the conjugates while their cellular uptake rate was improved significantly compared to the drug candidates. A correlation was found between me mbrane affinity properties a nd re sults of in vitro biological investiga tions. Analysis of physical/structural properties of SLB in contact with bioactive components and visualization of the structural change by a tomic-force microscopy (AFM) provided information on the type and route of molecular interaction of drug cons truction with lipid layers. The possible role of electrostatic interactions between lipid layer and drug candidates was tested in Langmuir-balance experiments using negatively charged lipid mixture (DPPC+DPPG). Especially the peptide conjugates presented increased membrane affinity due to cationic character of the peptide sequence selected for the conjugate formation. That is supposed to be one reason for the enhanced cellular uptake observed in vitro for MonoMac6 cell line. The conjugation of a ntitubercular agents to a peptidic carrier is a promising approach to enhance membrane affinity, cellular uptake rate and in vitro selectivity.
\end{abstract}

\section{Keywords}

Antitubercular, Drug peptide conjugate, Mycobacterium tuberculosis, Membrane affinity, Lipid membrane models, Cellular uptake

\section{Introduction}

Tuberculosis (TB) is a bacterial infection mainly caused by Mycobacterium tuberculosis (Mtb). TB remains a major public health problem worldwide and the first cause of mortality attributable to a single intracellular pathogen. Therefore there is an urgent need to develop new agents, active against the intracellular bacteria. The cellular uptake of the antituberculotics by infected host cells is limited. It is a possible approach to enhance the uptake rate of the antituberculars using peptide carriers [1]. The host cell specific delivery of the active compounds could increase the intracellular concentration [2]. In this study macrophage - as main host cell-specific conjugates were synthesised and characterised [2-6].

Tuftsin is a natural tetrapeptide (human: TKPR, canine: TKPK) produced by enzymatic cleavage of the Fc-domain of the heavy chain of IgG [4]. Tuftsin activates the immune system, including macrophages. C. M. Gupta et al. have developed tuftsin-bearing liposomes that not only enhance the 
host's resistance against a variety of infections but also serve as useful vehicles for the site-specific delivery of drugs in a variety of macrophage-based infections, such as leishmaniasis and TB [7]. A group of sequential oligopeptides based on tuftsin has been developed [5]. The synthetic oligotuftsins consist of tandem pentapeptide repeat units [TKPKG $]_{n}(n: 2,4,6,8)$ derived from the canine tuftsin sequence TKPK extended by a C-terminal Gly [3,5]. The canine tuftsin TKPK, where arginine residues is replaced by lysine, that has also basic character has similar biological activities like the human tuftsin TKPR [8]. However, the lysine residue in the sequence of TKPK can offer a new functional group for connection of a biologically active compound. With the addition of a glycine residue to the $\mathrm{C}$-terminal of TKPK racemisation free condensation of the fragments can be achieved to form larger oligomers [3]. These compounds are nontoxic, nonimmunogenic, biodegradable, and exhibit tuftsin-like biological properties, e.g. immunostimulatory activity and chemotactic activity on monocytes. The lysine residues in the sequence of oligotuftsins can offer functional groups for connection of a biologically active compound such as antituberculars. New heterotrimer TKPR[TKPKG $]_{2}$ oligotuftsin derivative (OT14) was applied in this study as carrier and targeting moiety. Molecular modelling study suggested a flexible structure for oligotuftsins and also demonstrated accessibility of the $\varepsilon$-amino group of each lysine residue [3]. In case of OT14 as new carrier Lys 8 and Lys13 were the most accessible out of the five Lys residues to form chemical linkage with antitubercular compound.

Small molecular drug candidates can be identified using the in silico docking method [9]. With this method compounds of a database $[10,11]$, that consists millions of moieties, were docked to the dUTPase enzyme (EC 3.6.1.23; Rv2697) [12], which plays a key role in the metabolism of the bacteria. dUTPase regulating the extent of uracil incorporation into DNA. Massive uracil incorporation may lead to cell death; dUTPase enzyme has therefore been recognized as a high-potential drug target in mycobacterial disease control. The efficacy of the compounds with in vitro antitubercular activity can be varied by synthetic optimization, so the starting compounds can be converted into drug candidates. After structure - activity studies with best ranked heteroaromatic pyrido-pyrimidine derivatives on virulent $M t b \mathrm{H}_{37} \mathrm{Rv}$, two of these new optimized antitubercular compounds (TB803, TB820 [13]) were conjugated to new oligotuftsin type peptide carrier OT14 through oxime bond.

To get information whether drugs can get through the barriers in living system such as cell membrane or bacterial cell wall is especially important for developments of new drug constructions with enhanced efficiency. Simplified lipid model systems were applied to study the details of membrane affinity of the bioactive compounds. The Langmuir monolayer of lipid molecules is a widely used membrane model due to its well defined and controlled structure as well as versatility in composition [12-19]. The molecular interaction with dissolved drug component is monitored by the increase of surface pressure allowing to deduce its penetration ability [20-23]. Furthermore, the lipid layer can be transferred from the water surface to a solid substrate opening the pos sible application of characterisation techniques of solid surfaces [24-26]. 
Supported lipid bilayer (SLB) prepared from phospholipid vesicles [27-29] was also used as model of cell membranes [30,31]. Once SLBs are constituted on the quartz crystal microbalance (QCM) sensor surface the sensitive detection of mass change allows to assess the interfacial interactions, the adsorption, desorption processes and membrane integrity [32-34]. With the aid of atomic force microscopy the results obtained were related to visual observations of the structural change of SLB induced by the interaction with the drug molecules.

In the present work we report on the synthesis of peptide conjugates using new tuftsin type carrier peptide and antitubercular drug candidates which were characterised by their membrane interaction using mono- and bilayer lipid model systems. Those properties werecompared to their in vitro behaviour observed in antimicrobial and cytotoxic activity studies as well as the results of cellular uptake measurements.

\section{Experimental}

\section{Materials}

1-Palmitoyl-2-oleoyl-sn-glycero-3-phosphocholine (POPC, Sigma-Aldrich) was used to form the lipid monolayer in the Langmuir trough and create the lipid bilayer on the sensor surface of QCM.

1,2-Dipalmitoyl-sn-glycero-3-phosphocholine (DPPC, Sigma-Aldrich) and a negatively charged lipid, 1,2-dipalmitoyl-sn-glycero-3-phospho-(1'-rac-glycerol) (sodium salt) (DPPG, Sigma-Aldrich) were mixed with 1:3 molar ratio and applied as a second model lipid system to mimic a negatively charged natural bacterial lipid envelope.

Chloroform, dichloromethane (purity $\geq 99.8 \%$ ) and methanol (purity $\geq 99 \%$ ) were used for preparing lipid solution and cleaning the Langmuir trough, all solvents were of analytical grade. Doubly distilled water checked by its conductivity $(<5 \mathrm{mS})$ and surface tension $(72.0 \mathrm{mN} / \mathrm{m}$ at $(25 \pm 0.5)^{\circ} \mathrm{C}$ ) was used for buffer preparation and it was the subphase in the Langmuir balance measurements.

A buffer consisting of $10 \mathrm{mM}$ Tris, $150 \mathrm{mM} \mathrm{NaCl}$ and $2 \mathrm{mM} \mathrm{CaCl}_{2}$ at $\mathrm{pH}=7.4$ (Sigma-Aldrich) was used for QCM measurements and liposome preparation.

For vesicle preparation, $10 \mathrm{mg}$ POPC powder was first dissolved in $1 \mathrm{~mL}$ mixture of chloroform and $5 \%(V / V)$ methanol in a glass flask. After 30 min mixing, the organic solvents were evaporated using a rotary evaporator and dried with a vacuum pump for two hours to remove any residual solvents. The dried lipid film was then rehydrated with $10 \mathrm{~mL}$ buffer. To prepare unilamellar vesicles, the stock $(1.0 \mathrm{~g} / \mathrm{L})$ and diluted $(0.1 \mathrm{~g} / \mathrm{L})$ lipid suspensions were forced through a polycarbonate membrane filter with $100 \mathrm{~nm}$ pore size for 31 times each at $30^{\circ} \mathrm{C}$ using an Avanti Mini-Extruder (Avanti Polar Lipids, USA) directly before QCM measurements. The hydrodynamic diameter of these 
particles is $(104 \pm 7) \mathrm{nm}$ which was determined by dynamic light scattering measurements (Brookhaven, BI-200SM goniometer system, BI-9000AT digital correlator, Coherent Genesis MX4881000STM laser-diode system operating at $488 \mathrm{~nm}$ wavelength and emitting vertically polarized light).

For solid phase peptide synthesis, analysis and purification commercial grade reagents were used without further purification. All amino acid derivatives and resins were purchased from Iris Biotech GmBH (Marktredwitz, Germany). Coupling agents, cleavage reagents and scavengers (1hydroxybenzotriazole hydrate ( $\mathrm{HOBt}), \mathrm{N}, \mathrm{N}^{\prime}$-diisopropylcarbodiimide (DIC), piperidine, 1,8diazabicyclo[5.4.0] undec-7-ene (DBU), trifluoroacetic acid (TFA), triisopropylsilane (TIS) were obtained from Sigma-Aldrich. 1-Methyl-2-pyrrolidon was obtained from Merck Hungary. N,NDimethylformamide (DMF), dichloromethane (DCM), diethylether and dimethylsulfoxide (DMSO) were purchased from Molar Chemicals Ltd (Hungary). Hydrochloric acid $(\mathrm{HCl})$, acetic acid $\left(\mathrm{CH}_{3} \mathrm{COOH}\right)$, solvent for HPLC (acetonitrile (ACN)) were purchased from Sigma-Aldrich.

TB803 (2-allylamino-4-oxopyrido[1,2-a]pyrimidine-3-carbaldehyde) and TB820 (4-oxo-2(pyrrolidin-1-yl)-pyrido[1,2-a]pyrimidin-3-carbaldehyde) were provided by Ubichem Pharma Services (Hungary).

For the in vitro studies (cellular uptake, MTT assay) RPMI-1640 medium, gentamicin and 3-(4,5dimethylthiazol-2-yl)-2,5-diphenyltetrazolium bromide (MTT) were obtained from Sigma-Aldrich. Dimethyl sulfoxide (DMSO) was purchased from Merck Hungary. Fetal calf serum (FCS) was purchased from Biocenter Ltd (Hungary). Phosphate buffered saline (0.01 M PBS, pH = 7.4) was prepared by dissolving $150 \mathrm{mmol} \mathrm{NaCl}, 8 \mathrm{mmol} \mathrm{Na} \mathrm{HPO}_{4} \cdot 2 \mathrm{H}_{2} \mathrm{O}, 2.7 \mathrm{mmol} \mathrm{KCl}$ and $15 \mathrm{mmol} \mathrm{KH}_{2} \mathrm{PO}_{4}$ (products of Sigma-Aldrich) in $1000 \mathrm{~mL}$ of deionized water. 24-well and 96-well flat-bottomed plates were the products of Sarstedt Ltd (Hungary).

\section{Synthesis of the peptide conjugates}

The TKPR[TKPKG $]_{2}$ (OT14) new heterotrimer analogue of the tuftsin sequence was produced on Fmoc-Rink Amide MBHA resin in an automated peptide synthesiser (Syro-I, Biotage, Sweden) using Fmoc/tBu strategy.

TB803 and TB820 compounds were conjugated to the OT14 peptide via oxime ligation. The $\mathrm{N}^{\varepsilon}$ 4-methyltrityl protecting groups of the side chain of two Lys residues were selectively removed with $2 \%$ TFA, $2 \%$ TIS in DCM $(6 \times 5 \mathrm{~min})$. After the 4-methyltrityl protecting group removal the resin was washed $(5 \times 1 \mathrm{~min}$ DCM) and neutralised ( $5 \times 1 \mathrm{~min} 10 \%$ DIEA in DCM) and free amino groups were reacted with Boc-aminooxyacetic acid. After peptide was removed from the resin with TFA in the presence of scavengers (cleavage mixture: 95\% TFA, 2.5\% TIS, 2.5\% $\mathrm{H}_{2} \mathrm{O}$ ), aminooxy-peptide was allowed to react with the TB803 or TB820 aldehyde compounds in solution (2.2 equivalent TB803 or 
TB820 was added to the peptide in $0.2 \mathrm{M} \mathrm{NaOAc/AcOH}$ buffer, $\mathrm{pH}=5.0$ and DMF $1: 1 \mathrm{~V} / \mathrm{V}$, the reaction was stirred at room temperature for 16 hours).

\section{Reverse Phase High-Performance Liquid Chromatography (RP-HPLC)}

The conjugates were purified on a KNAUER 2501 HPLC system (KNAUER, Germany) using a semipreparative Phenomenex Jupiter C18 column $(250 \mathrm{~mm} \times 10 \mathrm{~mm}$ ) with $10 \mu \mathrm{m}$ silica ( $300 \AA$ pore size, Gen-Lab Ltd., Hungary). Linear gradient elution (0-5 min 10\% B, 5-75 min 10-80\% B) with eluent A (0.1\% TFA in water) and eluent $B\left(0.1 \%\right.$ TFA in acetonitrile $\left./ \mathrm{H}_{2} \mathrm{O}(80: 20, \mathrm{~V} / \mathrm{V})\right)$ was used at a flow rate of $4 \mathrm{~mL} / \mathrm{min}$. Peaks were detected at $220 \mathrm{~nm}$. Analytical RP-HPLC was performed on an Exformma EX1600 HPLC system (Gen-Lab Ltd., Hungary) using an Agilent Zorbax SB-C18 column $(150 \mathrm{~mm} \times 4.6 \mathrm{~mm})$ with $5 \mu \mathrm{m}$ silica, $100 \AA$ pore size (Kromat Ltd, Hungary) as a stationary phase. Linear gradient elution (0-10 $\mathrm{min} 0 \% \mathrm{~B}, 10-30 \mathrm{~min} 0-90 \% \mathrm{~B}$ ) was used at a flow rate of $1 \mathrm{~mL} / \mathrm{min}$. Peaks were detected at $220 \mathrm{~nm}$.

\section{Mass Spectrometry (MS)}

Electrospray (ESI)-mass spectrometric analysis were carried out on an Esquire 3000+ ion trap mass spectrometer (Bruker Daltonics, Germany). Spectra were acquired in the 50 - $2500 \mathrm{~m} / \mathrm{z}$ range. Samples were dissolved in a mixture of $0.1 \%$ acetic acid in acetonitrile/ $\mathrm{H}_{2} \mathrm{O}$ (50:50, V/V) (Fig. 1, Table 2).

\section{Monolayer studies}

The lipid layer measurements were accomplished by a computer controlled KSV MiniMicro Langmuir balance (KSV Instruments, Finland). The trough was mounted on an aluminium base with built-in channels for temperature control of the subphase and enclos ed in an environment chamber. The trough was made of Teflon and the barrier from polyoxymethylene (POM). The experiments were performed at $(25 \pm 0.5)^{\circ} \mathrm{C}$.

Lipids were dissolved in chloroform, and $50 \mu \mathrm{L}$ of $0.2 \mathrm{~g} / \mathrm{L}$ solutions were applied by a microsyringe to form monolayer on the water surface. The solvent was allowed to evaporate for $15 \mathrm{~min}$. By two movable barriers the lipid layer was compressed into a dense and symmetric monolayer while the surface pressure and the area were continuously recorded. The surface pressure was measured by the Wilhelmy method using a chromatography paper sensor (Whatman Chr1).

The lipid monolayer was compressed to a given surface pressure $(20 \mathrm{mN} / \mathrm{m})$ for penetration experiments. Drugs and drug-conjugates were dissolved in water and were injected below the 
compressed lipid monolayer at a fixed barrier position to attain a final concentration of $2 \mu \mathrm{M}$ in the subphase. The change in surface pressure as the indicator of drug penetration was recorded for $1 \mathrm{~h}$. The degree of penetration was given as the average of two independent measurements with a deviation $<0.5 \mathrm{mN} / \mathrm{m}$.

\section{Bilayer studies}

\section{QCM (Quartz Crystal Microbalance) measurements}

A QCM200 (Stanford Research Systems, USA) system was used to create lipid bilayer on $\mathrm{SiO}_{2}$ coated quartz crystal ( $5 \mathrm{MHz}$ AT-cut) and study the interactions with drug candidates and their peptide-conjugates. The equipment includes a flow-through cell, an oscillator and an analyser. The flow cell was connected to a peristaltic pump applying a flow rate of $0.2 \mathrm{~mL} / \mathrm{min}$. Experiments were performed at $(25 \pm 0.1)^{\circ} \mathrm{C}$. After achieving a stable baseline with continuous flow of the buffer in the liquid flow cell, $1 \mathrm{~mL}$ freshly prepared POPC liposome system with a concentration of $0.1 \mathrm{~g} / \mathrm{L}$ was injected. Following the formation of lipid bilayer and washing with buffer $1 \mathrm{~mL}$ drug solution was injected. The peristaltic pump was switched off for an hour so that interactions between the bilayer and the drug molecules can take place. Finally the system was washed with buffer. During measurements the resonance frequency $(f)$ and motional resistance $(R)$ of the sensor crystal were recorded.

The adsorbed mass $(\Delta m)$ on the sensor surface can be related to changes in resonance frequency $(\Delta f)$ through the Sauerbrey equation [35]:

$$
\Delta f=-C_{\mathrm{f}} \cdot \Delta m
$$

where $C_{\mathrm{f}}$ corresponds to the sensitivity factor for the crystal $\left(56.6 \mathrm{~Hz} \times \mu \mathrm{g}^{-1} \times \mathrm{cm}^{2}\right.$ for a $5 \mathrm{MHz}$ AT-cut quartz crystal at room temperature). Measurements were done in triplicates.

\section{AFM (Atomic Force Microscopy) measurement}

Sensor surfaces were investigated by atomic force microscopy (AFM) (Park System, XE-100, South Korea) after QCM measurements to visualize changes in the structure of the lipid membrane following their interaction with the drug candidates. Measurements were performed in air at $25^{\circ} \mathrm{C}$ in non-contact mode. The cantilever (NSC15/AIBS, MicroMasch, force constant $40 \mathrm{~N} / \mathrm{m}, 325 \mathrm{kHz}$ resonance frequency) made of $\mathrm{Si}_{3} \mathrm{~N}_{4}$ has a tip curvature radius less than $10 \mathrm{~nm}$ with an $\mathrm{Al}$-coated reflective back side. A scanning rate of $1.0 \mathrm{~Hz}$ was used with a scan window of $5 \times 5 \mu \mathrm{m}^{2}$. The images were analysed using the XEI 1.8 program (Park Systems, South Korea) to obtain information on the lipid bilayer and the effect of the interactions with peptides and conjugates. 


\section{Evaluation of in vitro antimycobacterial activity on Mycobacterium tuberculosis $\mathrm{H}_{37} \mathrm{Rv}$}

In vitro antimycobacterial activity of the compounds was determined on $M$. tuberculosis $\mathrm{H}_{37} \mathrm{Rv}$ (ATCC 27294) by serial dilution method in Sula semisynthetic medium [36], which was prepared inhouse $(\mathrm{pH}=6.5)$. Compounds were added to the medium as DMSO solutions at 10 various doses (range of final concentration was between 0.5 and $100 \mu \mathrm{g} / \mathrm{mL}$ ). Minimal inhibitory concentration (MIC) was determined after incubation at $37^{\circ} \mathrm{C}$ for 28 days. MIC was the lowest concentration of a compound at which the visible inhibition of the growth of $M$. tuberculosis $\mathrm{H}_{3} 7 \mathrm{Rv}$ occurred. In order to confirm growth inhibition, colony forming unit (CFU) was determined by subculturing from the Sula medium onto drug-free Löwenstein-Jensen solid [37] medium Samples were incubated for 28 days. Experiments were repeated at least two times $[2,5,12,13,38,39]$. All experiments with virulent human pathogen $M$. tuberculosis $\mathrm{H}_{37} \mathrm{Rv}$ were carried out in a bio-safety level 3 (BL-3) containment area at Korányi National Tuberculosis Hospital (Budapest, Hungary).

\section{Determination of in vitro cytotoxic activity on MonoMac6 cells}

MonoMac6 cell cultures (DSMZ no.: ACC 124, Deutsche Sammlung von Mikroorganismen and Zellkulturen $\mathrm{GmbH}$, Braunschweig, Germany) were maintained in RPMI-1640 medium containing 10\% FCS, $2 \mathrm{mM} \mathrm{L-glutamine,} \mathrm{and} 160 \mu \mathrm{g} / \mathrm{mL}$ gentamycin at $37^{\circ} \mathrm{C}$ in $5 \% \mathrm{CO}_{2}$ atmosphere. The cells were plated on 96-well plates $\left(10^{4}\right.$ cells $/ 100 \mu \mathrm{L}$ medium/well $)$ and after $24 \mathrm{~h}$ incubation at $37^{\circ} \mathrm{C}$, cells were treated for $16 \mathrm{~h}$ (overnight, ON) with the compounds dissolved in serum free RPMI-1640 medium $\left(c_{\mathrm{DMSO}}=1.0 \%, \mathrm{~V} / \mathrm{V}\right)$ at $5 \times 10^{-2}$ to $5 \times 10^{2} \mu \mathrm{M}$ concentration range. Control cells were treated with serum free medium only or with DMSO containing serum free medium $(c=1.0 \%, \mathrm{~V} / \mathrm{V})$ at $37^{\circ} \mathrm{C}$. After the treatment and incubation, cells were washed twice with serum-free medium (centrifugation: $1000 \mathrm{rpm}, 5 \mathrm{~min})$ and the cell viability was determined with (4,5-dimethylthiazol-2-yl)-2,5diphenyltetrazolium bromide (MTT)-assay [40-42]. $45 \mu \mathrm{L}$ MTT solution ( $2 \mathrm{mg} / \mathrm{mL}$ ) was added to each well and during $3.5 \mathrm{~h}$ incubation purple crystals were formed by mitochondrial dehydrogenase enzyme present in the living cells. After incubation cells were centrifuged for $5 \mathrm{~min}$ at $2000 \mathrm{rpm}$ and the supernatant was removed. Crystals were dissolved in DMSO and the optical density (OD) of the samples was determined at $\lambda=540$ and $620 \mathrm{~nm}$ using an ELISA Reader (Labsystems MS reader, Helsinki, Finland). OD620 was subtracted from OD540. The percent of cytotoxicity was calculated using the following equation: cytotoxicity $(\%)=100 \times\left(1-O D_{\text {treated }} / O D_{\text {control }}\right)$, where $O D_{\text {treated }}$ and $\mathrm{OD}_{\text {control }}$ correspond to the optical densities of treated and control cells, respectively. Cytotoxicity (\%) was plotted as a function of concentration, fitted to a sigmoidal curve and the $50 \%$ inhibitory concentration $\left(\mathrm{IC}_{50}\right)$ value was determined from these curves. Each experiment was repeated at least 2 times and the average $\mathrm{IC}_{50}$ values were presented. The curves were defined using Microcal Origin 7.5 software. 


\section{Determination of in vitro cellular uptake profiles of the compounds by flow cytometry}

The measurements of the cellular uptake of the compounds were evaluated by flow cytometry (BD LSR II, BD Biosciences, USA) on MonoMac6 human monocytic cell line. Cells were harvested in the logarithmic phase of growth and plated on a 24 -well tissue culture plate $\left(10^{5}\right.$ cells $/ 1 \mathrm{~mL}$ medium/well) $24 \mathrm{~h}$ prior to the experiment. Compounds were dissolved in serum free RPMI-1640 medium, and running dilutions were prepared. The highest concentration of the compounds on the cells was $250 \mu \mathrm{M}$. Cells were incubated with compounds TB820, TB803, TB820-OT14, TB803-OT14 for $60 \mathrm{~min}\left(37^{\circ} \mathrm{C}, 5 \% \mathrm{CO}_{2}\right.$ atmosphere). After centrifugation (1000 rpm, $\left.5 \mathrm{~min}, 4^{\circ} \mathrm{C}\right)$, the supernatant was removed, and $100 \mu \mathrm{L}$ of $1 \mathrm{mM}$ trypsin was added to the cells. The effect of trypsin was stopped by $900 \mu \mathrm{L}$ Hepes buffer HPMl (HPMl; $100 \mathrm{mM} \mathrm{NaCl}, 5.4 \mathrm{mM} \mathrm{KCl}, 0.4 \mathrm{mM} \mathrm{MgCl}, 0.04 \mathrm{mM} \mathrm{CaCl}_{2}$, $10 \mathrm{mM}$ Hepes, $20 \mathrm{mM}$ glucose, $24 \mathrm{mM} \mathrm{NaHCO}_{3}$ and $5 \mathrm{mM} \mathrm{Na}_{2} \mathrm{HPO}_{4}$ at $\mathrm{pH}=7.4$ [43] containing $10 \%$ FCS, and the cells were transferred from the plate to FACS-tubes. Cells were centrifuged (1000 rpm, $5 \mathrm{~min}, 4^{\circ} \mathrm{C}$ ) and the supernatant was removed. After this procedure, cells were resuspended in $500 \mu \mathrm{L}$ HPMI, and the intracellular fluorescence intensity of MonoMac6 cells was monitored (488 nm (Coherent Sapphire, $22 \mathrm{~mW}$ ) laser, channel PE LP550 (emission at $\lambda=550 \mathrm{~nm}$ )) which is proportional to the cellular uptake. Data were analysed with FACSDiVa 5.0 software. All measurements were performed in duplicate. The graph was generated using Prism (version 5) software.

\section{Results and Discussions}

New pyridopyrimidine derivatives were defined using in silico docking method [44] prior to chemical optimization based on structure - activity studies [31,45]. The in vitro antimycobacterial activity of the compounds was characterised by the determination of the minimal inhibitory concentration ( $\mathrm{MIC}$ ) on $\mathrm{M}$. tuberculosis $\mathrm{H}_{37} \mathrm{Rv}$ culture with 4-week exposure period [2]. For further chemical modification a pyrido-pyrimidine derivative (2-allylamino-3-allyliminomethylpyrido[1,2a]pyrimidin-4-one) was chosen. After structure - activity studies with pyrido-pyrimidines two of these new optimized antitubercular compounds (TB803, TB820 [13]) were conjugated to a new oligotuftsin derivative heterotimer peptide carrier OT14 through oxime bond (Fig. 1). We observed that the Lys 8 and Lys 13 residues were the most accessible out of the five Lys residues of OT14 carrier to form chemical linkage with antitubercular compound.

TB803-OT14 and TB820-OT14 conjugates were carefully characterise d by mass spectrometry, analytical RP-HPLC and amino acid analysis (data not shown). The compounds exhibited fluorescence when excited at $488 \mathrm{~nm}$ enabling their detection in cellular uptake measurements (emission at $\lambda=550 \mathrm{~nm}$ ) without additional labelling. 


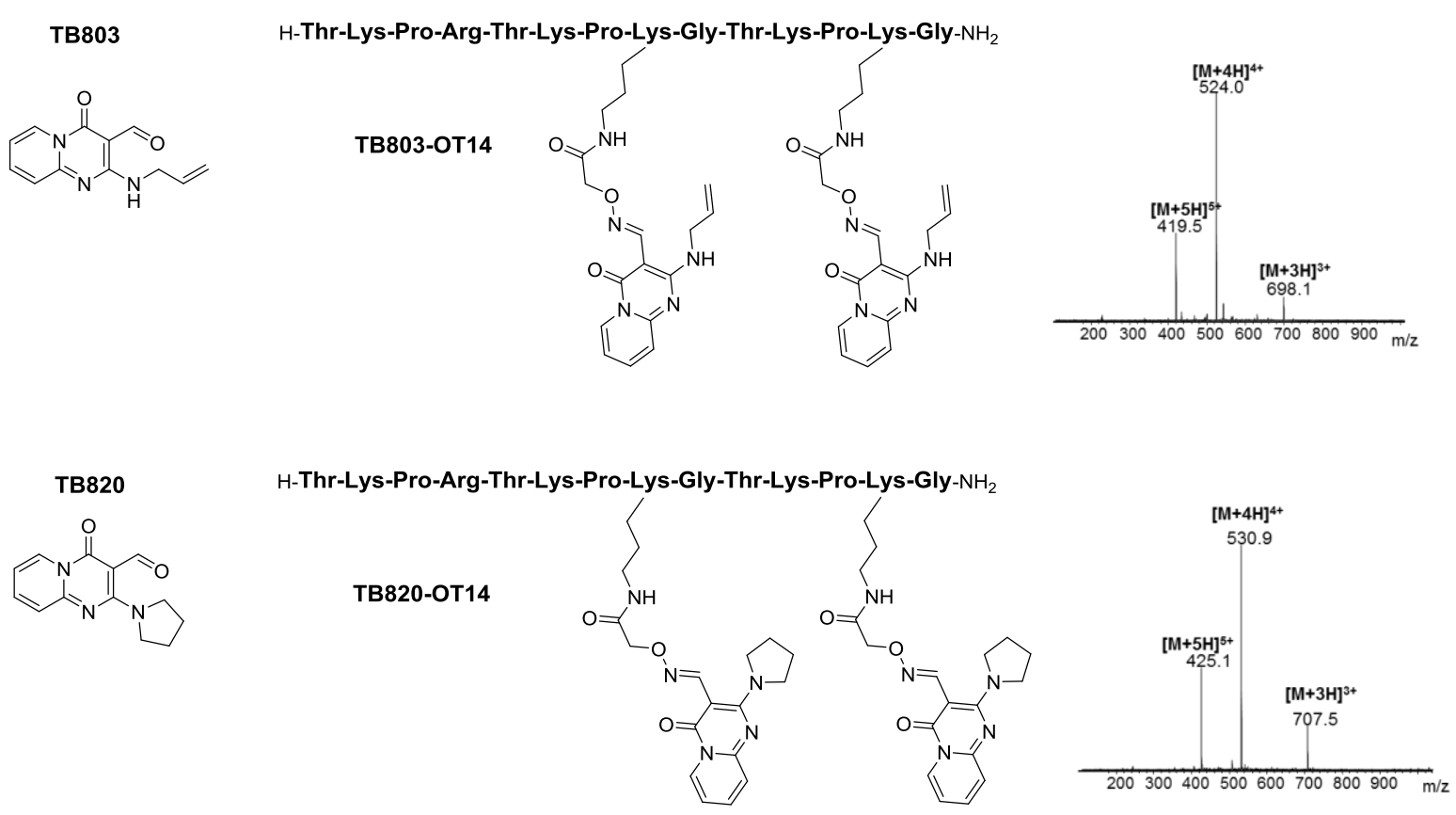

Fig. 1. Chemical structure of TB803, TB820 compounds, their peptide conjugates, and ESI-MS mass spectra of the conjugates. TB803 and TB820 compounds were conjugated to the peptide carriers via oxime ligation.

\section{Monolayer studies}

The membrane affinity of the drug candidates and conjugates was studied in Langmuir-balance experiments, where the adsorption and/or penetration into the lipid layer were detected. POPC and DPPC+DPPG mixture as characteristic components of eukaryotic cell membrane or bacterial cell envelope were chosen to form the lipid monolayers as membrane model.

Surface pressure - area isotherms were recorded for the lipid monolayer systems. The isotherm of POPC shows a gradual change with molecular area and does not present the phase transition typical for DPPC. This shape in connection with the low phase transition temperature $\left(-2^{\circ} \mathrm{C}\right)$ of POPC is in agreement with the previously published results $[46,47]$. The DPPC+DPPG mixture conversely shows the distinct states of lipid monolayer characteristic for pure DPPC. The presence of 25 mol\% of the anionic DPPG has negligible effect on the phase behaviour of the lipid film however, could greatly influence the interaction with cationic peptides [48].

Surface pressure of $20 \mathrm{mN} / \mathrm{m}$ was selected as starting value of the compressed lipid film for the penetration experiments which is high enough to represent the packing of lipid molecules in the membrane and appropriate value to allow evaluation of the possible differences in the penetration ability of the various components studied.

Increase of surface pressure $(\Delta \pi)$ was detected as function of the time following the introduction of drug compound into the subphase of lipid monolayer. In the first period after 
injection a fast increase of the surface pressure was observed. After approximately $5 \mathrm{~min}$ the change of surface pressure became smaller. $\Delta \pi$ values determined at $\mathrm{t}=1 \mathrm{~h}$ characterising the penetration ability of the drugs are summarized in Table 1.

Table 1. Penetration $(\Delta \pi)$ of drug candidates into lipid monolayer determined in Langmuir balance experiments as well as frequency $(f)$ and resistance $(R)$ in stage 5 at concentration of $430 \mu \mathrm{M}$ determined in QCM measurements. $\sigma_{\mathrm{M}}$ values are the standard error of the mean of three replicate measurements.

\begin{tabular}{|c|c|c|c|c|c|c|c|c|c|}
\hline \multicolumn{5}{|c|}{$\begin{array}{l}\text { Penetration measurements } \\
\qquad \Delta \pi(\mathrm{mN} / \mathrm{m})\end{array}$} & \multicolumn{5}{|c|}{ QCM measurements } \\
\hline Drug & POPC & $\sigma_{\mathrm{M}}$ & $\begin{array}{l}\text { DPPC+ } \\
\text { DPPG }\end{array}$ & $\sigma_{\mathrm{M}}$ & $\Delta f_{5} / \mathrm{Hz}$ & $\sigma_{M}$ & $\Delta R_{5} / \Omega$ & $\sigma_{\mathrm{M}}$ & $\begin{array}{c}\Delta f_{5, \mathrm{~m}} / \\
\mathrm{Hz}\end{array}$ \\
\hline TB803 & 1.0 & 0.2 & 0.4 & 0.2 & 1.0 & 0.3 & 0.0 & 0.3 & 1.0 \\
\hline $\begin{array}{l}\text { TB803- } \\
\text { OT14 }\end{array}$ & 2.7 & 0.2 & 5.6 & 0.2 & -4.0 & 0.6 & 0.8 & 0.1 & -2.6 \\
\hline TB820 & 0.8 & 0.2 & 1.4 & 0.2 & 2.2 & 0.4 & 0.2 & 0.1 & 2.6 \\
\hline $\begin{array}{l}\text { TB820- } \\
\text { OT14 }\end{array}$ & 1.8 & 0.3 & 4.8 & 0.3 & -0.8 & 0.4 & 1.6 & 0.2 & 2.2 \\
\hline
\end{tabular}

Small drug molecules just slightly penetrate into the lipid monolayers. The penetration affinity is significantly increased for the peptide conjugates (TB803-OT14, TB820-OT14), especially when electrostatic interactions with the charged DPPC+DPPG monolayer are effective. The highest membrane affinity was obtained for the TB803-OT14 considering any of the lipid layers.

\section{Bilayer studies}

The membrane affinity of the drug candidates and their peptide conjugates were characterised by their interaction with supported lipid bilayers. QCM-R technique was employed to follow the interactions at the SLB - liquid interface. The supported bilayers were prepared in situ in the QCM liquid cell by spreading POPC liposomes on silica coated QCM sensor crystals. Mass changes were detected as changes in the resonance frequency of the sensor quartz crystal. The increased mass of the sensor leads to the decrease of vibrational frequency. In addition to that the QCM-R technique allows for the simultaneous and independent determination of the motional resistance of the sensor which can be used to interpret changes in the structure of the liquid-solid interface. Fig. 2 shows a typical measurement curve. Following the stable baseline (1) liposomes were introduced (2) and 
after spreading and rupture of liposomes a lipid bilayer was formed (3). Then the bioactive compound was injected and $\Delta f$ and $\Delta R$ showed the interaction of drug or drug-conjugate with lipid bilayer (4) followed by a rinsing with buffer (5).

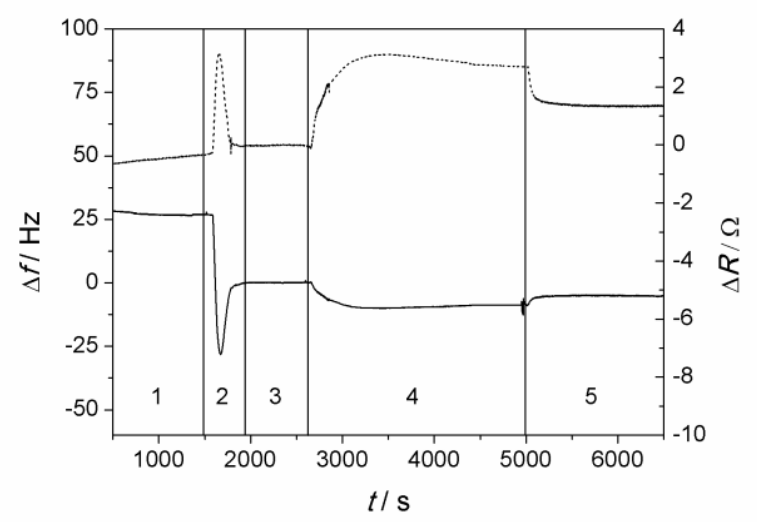

Fig. 2. Changes in the resonance frequency ( $\Delta f$, solid line) and the motional resistance ( $\Delta R$, dashed line) of the QCM sensor crystal over time. The measurements could be divided into sequences: 1 : buffer baseline with bare silica surface; 2: introduction of liposome, spreading, formation of lipid bilayer; 3 : buffer baseline with lipid bilayer; 4 : addition of drug candidate solution, interaction with lipid layer; 5: washing with buffer.

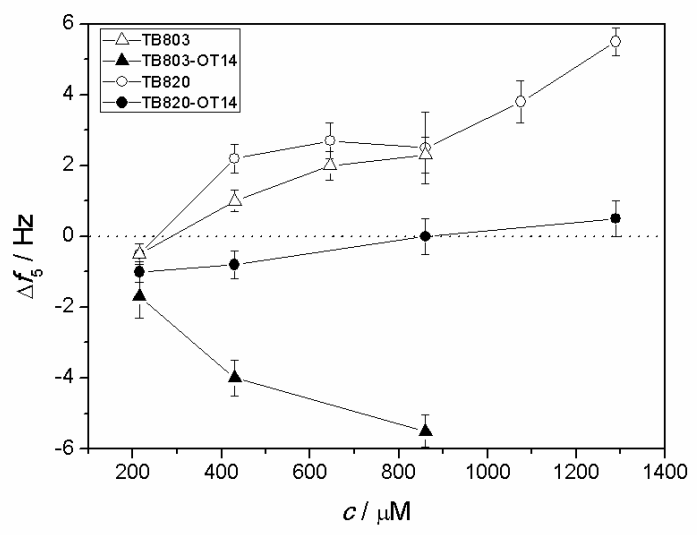

Fig. 3. Frequency change $\left(\Delta f_{5}\right)$ at the end of section 5 in the QCM experiment indicating interaction of TB803 ( $\triangle$ ), TB820 (O) and their peptide conjugates (closed symbols) with POPC bilayer as a function of concentration. Error bars represent the standard error of the mean of three replicate measurements.

Frequency change characterising the interaction with SLB can be seen as a function of concentration in Fig. 3. Behaviour of TB803 and TB820 show relevant difference from their conjugates. The values of the two drug candidates follow the same trend indicating slight mass reduction during the interaction. (TB803 cannot be measured at higher concentrations due to its limited solubility.) On the other hand the conjugates differ also from each other. The frequency values for TB803-OT14 significantly decrease with increasing concentration which is not the case for TB820-OT14. The interaction of TB803-OT14 with lipid bilayer suggests a clear affinity resulting in 
mass increase of the surface layer. The behaviour of the TB820-OT14 is different in both the degree and sign of frequency change.

Frequency and resistance changes relevant for the interaction were determined relative to the values corresponding to the intact lipid bilayer (stage 3). $\Delta f_{5}$ and $\Delta R_{5}$ are the values after $15 \mathrm{~min}$ washing with buffer following the 40 min contact with the drug solution. The results for the cases of the drug concentration of $430 \mu \mathrm{M}$ are collected in Table 1.

For the more detailed interpretation of the data and to get information on the possible structural changes in the surface layer it should be considered that the changes in the resonance frequency consist of two contributions. One is the change in mass on the sensor surface; the other is from the changes in the viscoelastic properties of the liquid phase near the surface. If the viscosity and density of the liquid medium remain constant during the measurement, the viscous loading of the sensor can still change due to the formation of non rigid layers. This means that measuring only the frequency in liquid it is not possible to differentiate between mass changes and structural changes of the interface. The independent measurement of the motional resistance provides a way to detect sensitively changes in the viscoelastic properties of the surface layer. Using the Butterworth-Van Dyke equivalent circuit model a linear relationship can be derived between the changes in the motional resistance and the density-viscosity $\left(\rho_{L} \eta_{L}\right)^{1 / 2}$ of the surface layer [49]

$$
\Delta R=\left(\frac{n \omega L}{\pi}\right)\left(\frac{2 \omega \rho_{\mathrm{L}} \eta_{\mathrm{L}}}{\rho_{\mathrm{q}} \mu_{\mathrm{q}}}\right)^{1 / 2},
$$

where $n$ is the number of sides in contact with liquid, $\omega$ is the angular frequency at resonance, $L$ is the inductance of the unperturbed resonator, $\rho_{\mathrm{q}}$ and $\mu_{\mathrm{q}}$ are the density and shear modulus of quartz. Similarly the effect of viscous loading on the resonance frequency can be estimated using Kanazawa Gordon equation $[50,51]$

$$
\Delta f=-f_{0}^{3 / 2}\left(\frac{\rho_{\mathrm{L}} \eta_{\mathrm{L}}}{\pi \rho_{\mathrm{q}} \mu_{\mathrm{q}}}\right)^{1 / 2},
$$

where $f_{0}$ is the resonance frequency of the unloaded crystal.

Considering that the motional resistance is mainly affected by the changes in the viscoelastic properties of the surface layer while mass changes also add to the measured frequency changes, these two equations can be used to estimate the viscous loading contribution in the total frequency. First $\Delta\left(\rho_{L} \eta_{L}\right)^{1 / 2}$ is calculated using Eq. 2 followed by the estimation of the $\Delta f$ due to changes in the sensor surface structure and/or environment using Eq. 3. Subtracting this contribution from the total frequency change the mass change contribution of the frequency $\left(\Delta f_{5, \mathrm{~m}}\right)$ can be calculated. These calculated values are also presented in Table 1. 
Increased resistance value is the signal of the expansion of the surface layer, which becomes looser. Accordingly, a decrease in the motional resistance indicates the layer becoming denser, more rigid.

For the various drug candidates a definite distinction can be made based on the exhibited motional resistance changes depending on the structure of the molecules. For the small drug candidates the change in motional resistance is close to zero indicating no significant variation in the viscous property of the layer. The peptide conjugates of the two drug molecules however, present marked increase of motional resistance. That can be considered as the viscoelastic changes at the interface due to the interaction with SLB, especially for TB803-OT14. Considering these results the peptide conjugates are able to loosen the lipid bilayer increasing the viscosity of the surface layer.

Simultaneously, the calculated components of the frequency change responsible for mass change $\left(\Delta f_{5, \mathrm{~m}}\right)$ are positive except for the case of TB803-OT14. That small mass reduction indicates that the molecules interact slightly with the lipid membrane, a partial displacement of SLB can occur.

On the contrary $\Delta f_{5, m}$ is a negative value indicating mass increase for drug conjugate TB803OT14. This strong attraction is in accordance with the highest membrane affinity of that conjugate obtained in lipid monolayer experiment.

Morphology studies of the lipid layers using AFM could help to understand the changes observed during the QCM measurements. Representative AFM topography images of the different systems are shown in Fig. 4.

AFM studies confirm that the lipid membranes remain almost intact following the interaction with TB820 (Fig. 4. B) and TB803, only small increase in surface roughness could be observed when comparing pictures with those of pure POPC membrane (Fig. 4. A). That can be related to the limited disturbance of SLB by the slight interaction. 

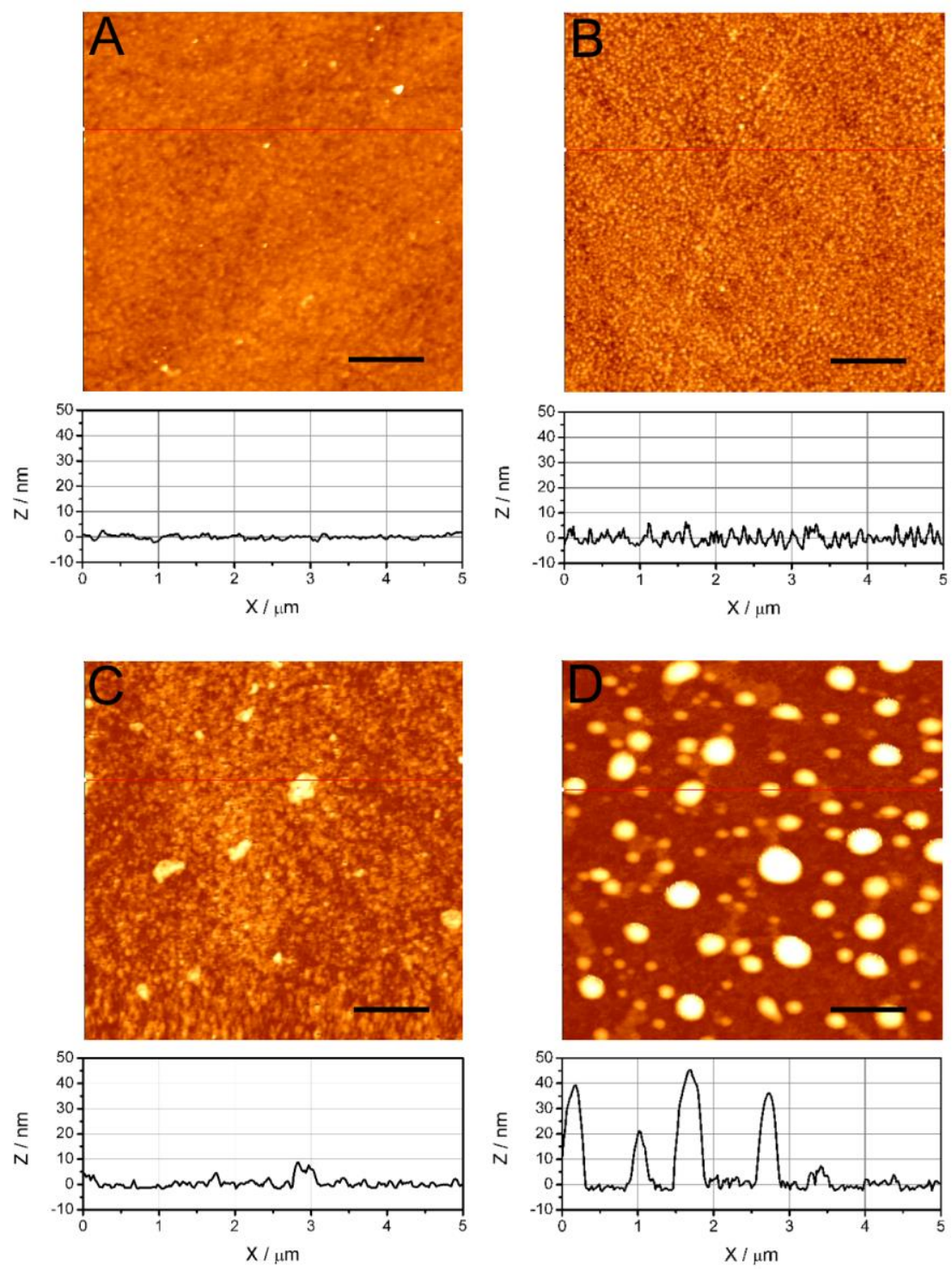

Fig. 4. AFM topographic images of pure POPC membrane (A), POPC membrane after interaction with small molecule TB820 (B) and peptide conjugates TB803-OT14 (C) and TB820-OT14 (D) with cross section profiles. Scale bar represents $1 \mu \mathrm{m}$.

AFM image of the lipid layer following interaction with the TB803-conjugate revealed that only an increase in surface roughness can be detected along with some small sized ( $5-10 \mathrm{~nm}$ high) aggregates (Fig. 4. C). This is consistent with the QCM results where a significant drop in resonant frequency corresponds with the addition of mass onto the lipid layer.

In the case of TB820-OT14 a considerably different morphology was observed. Although there are only small mass changes during the binding process the structure of lipid bilayer is drastically changed. This is visualized in AFM in Fig. 4. D. The uniform bilayer structure is destroyed. The main feature of these images is the presence of large aggregates while parts of the bilayer are still observable. If we calculate the total volume of these aggregates it turns out to be the same volume as a continuous POPC bilayer would have. For multiple images this turned out to be consistent within $5 \%$ error. This interfacial restructuring is upheld by the QCM results. The presence of the loose 
aggregates would lead to an increase in the viscous loading as observed while most of the material remained on the surface.

The difference in the behaviour of the two conjugates could be attributed to the structure of the small molecules. TB803 with its allylamine group would have a smaller surface area than TB820 with the pyrrolidine group. This could be the reason for the effect TB820-conjugate had on the POPC membrane. Due to its larger surface area the insertion of the molecule would lead to a more disrupted membrane leading to the eventual destruction of the bilayer structure.

In conclusion two main effects can be distinguished considering the influence of drug interacting with lipid layers (Fig. 5). In the case of the small molecules a weak interaction is proposed, supported by their low membrane affinity. The presence of the molecules at the interface disturbs the ordered structure of the membrane in some extent which might lead to a loss of small fraction of membrane lipids. In the second case with the peptide conjugates the peptide chains bind to the lipid membrane via electrostatic interactions, disturbing the well ordered membrane structure. The hydrophobic drug parts of the molecules can then penetrate more easily the membrane. Depending on the size of the small molecular drug part the conjugates either disturb or completely destroy the lipid bilayer structure. 


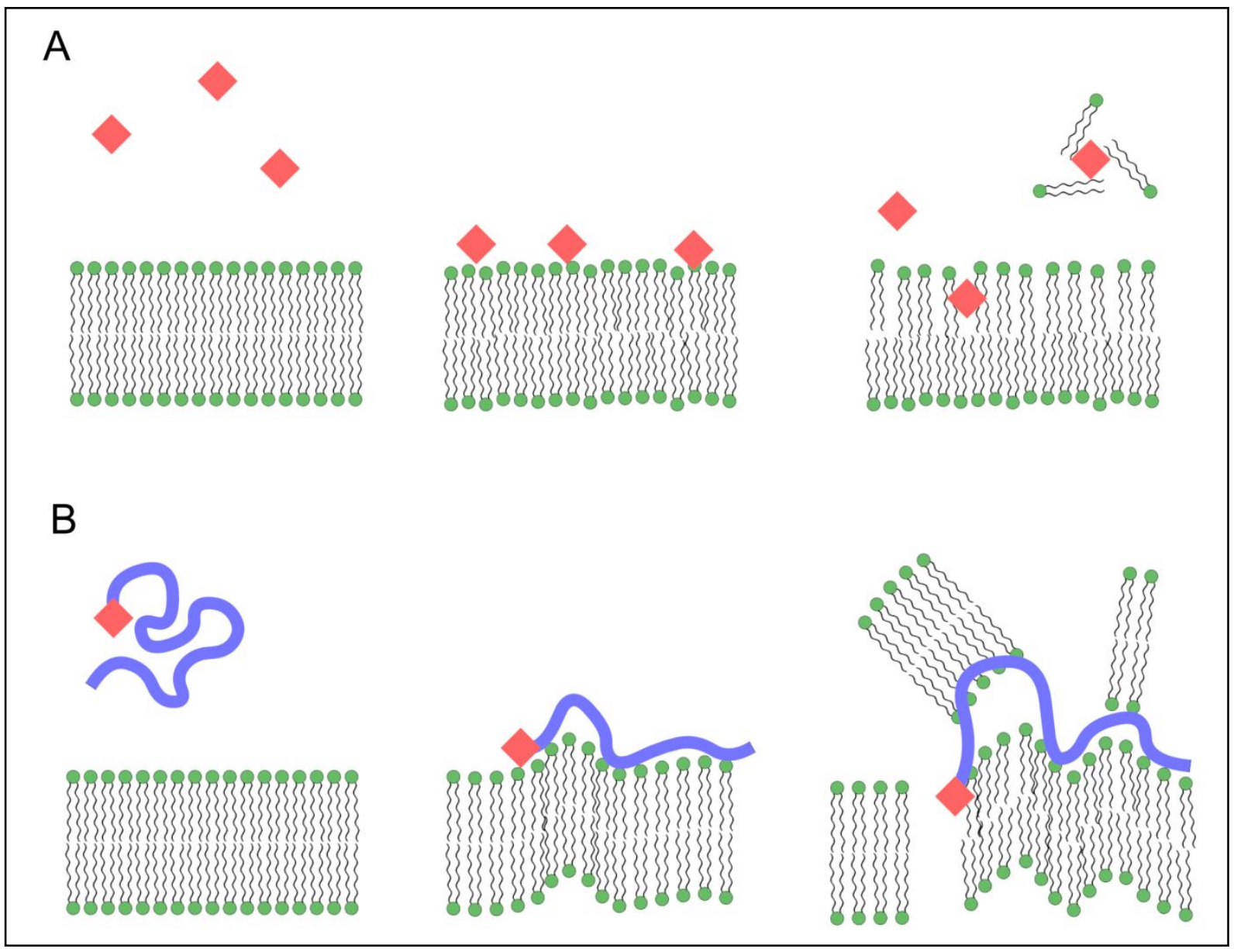

Fig. 5. Possible mode of interaction between lipid bilayers and TB803, TB820 (A) and their peptide conjugates (B).

\section{In vitro bioactivity studies}

Minimal inhibitory concentration (MIC) values of the compounds on $M$. tuberculosis $\mathrm{H}_{37} \mathrm{Rv}$

Minimal inhibitory concentration (MIC) of the conjugates, the carrier peptide and the free antituberculars TB803 and TB820 were studied on M. tuberculosis $\mathrm{H}_{37} \mathrm{Rv}$, which is a human pathogen responsible for the infectious disease of tuberculosis. TB803 and TB820 compounds have outstanding inhibitory effect on the bacterial culture. The TB803-OT14 conjugate exhibited uniquely good activity, but TB820-OT14 effect was excellent. The carrier peptide itself was not effective on bacterial culture. We observed that the antitubercular activity of the free TB803 and TB820 was essentially preserved after conjugation to peptide carriers through oxime bond (Table 2). These results suggested the significant in vitro antimycobacterial effect of the compounds remained attractive in the conjugate. 


\section{Table 2}

Characteristics of the compounds.

\begin{tabular}{|c|c|c|c|c|c|}
\hline Compound & $M^{a}$ & $\begin{array}{c}R t^{b} \\
(\min )\end{array}$ & $\begin{array}{l}M I^{c} \\
(\mu \mathrm{M})\end{array}$ & $\begin{array}{l}I_{50}{ }^{d} \\
(\mu \mathrm{M})\end{array}$ & $\begin{array}{c}\text { Selectivity } \\
\text { index }^{e}\end{array}$ \\
\hline TB803 & 229.2 & 24.5 & 4 & $>500$ & $>125$ \\
\hline TB803-ОT14 & 2091.8 & 21.4 & 38 & $>500$ & $>13$ \\
\hline TB820 & 243.3 & 23.0 & 4 & $>500$ & $>125$ \\
\hline TB820-0T14 & 2151.5 & 21.2 & 9 & $>500$ & $>56$ \\
\hline \multicolumn{6}{|c|}{ 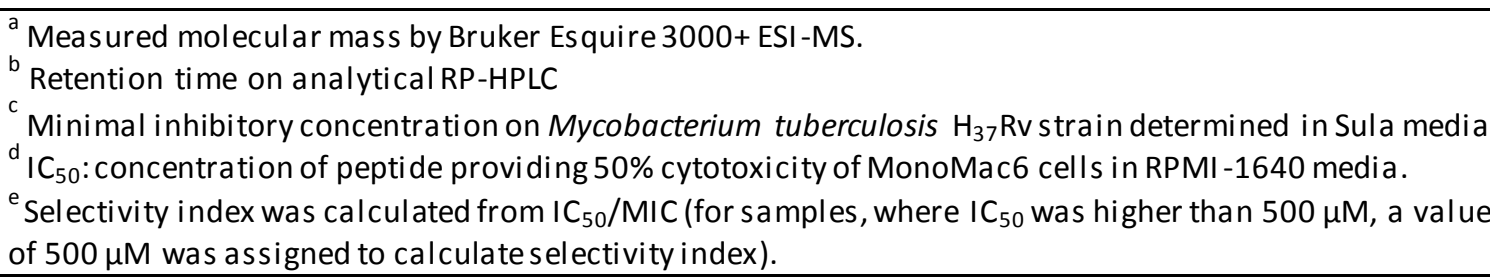 } \\
\hline
\end{tabular}

\section{In vitro cytotoxicity on human MonoMac- 6 cells}

Determination of the in vitro cytotoxic effect of the compounds was carried out on human monocytic cell line MonoMac6 using MTT (3-(4,5-dimethylthiazol-2-yl)-2,5-diphenyltetrazolium bromide) assay. The IC50 values (the concentration which decreases the viability of the cells to $50 \%$ from the maximal viability) were determined from the dose-response curves (Table 2). The MonoMac6 cells are considered as an in vitro model of the host cell macrophages. The selectivity indexes $(\mathrm{SI})$ related to each bacterial strain were determined as a ratio of the $\mathrm{IC}_{50}$ value for cytotoxic activity to the MIC value (Table 2). The compounds did not influence the cell viability up to $500 \mu \mathrm{M}$ concentration and they showed good selectivity due to the cytotoxicity (low IC $\mathrm{I}_{50}$ value) on human MonoMac- 6 cells (Table 2).

\section{In vitro cellular uptake profile of the compounds}

The cellular uptake of the free TB803, TB820 and their peptide-conjugates was determined by flow cytometry on MonoMac6 human monocytic cell culture. MonoMac6 cells are phagocytic and were established as a cell line, which appears to have phenotypic and functional characteristics of mature blood monocytes. MonoMac- 6 line is frequently used as a host cell model for intracellular bacteria such as $M$. tuberculosis. Small molecular weight organic compounds such as the new antitubercular candidates and cationic peptides are known to bind to the outside of the cell membrane and can thereby give false positive fluorescence signals, as fluorescence analysis cannot discriminate between internalized or surface bound compounds. Protocols to reduce fluorescence signals from surface bound compounds include treating cells with trypsin. Prior to flow cytometry measurements the MonoMac- 6 cells were trypsinised to reduce the surface structure of the cells by 
its proteolytic action in order to remove the aspecifically bound and not intracellular fluorescent compounds and peptide conjugates [52-54].

All compounds, TB803 and its conjugate are fluorescent. Minimal internalization was detected for TB803 and TB820 compare to that of the untreated control (Fig. 6). Conjugation to OT14 peptide significantly increased cellular uptake of the compounds, the treatment with the conjugates has resulted in the highest intracellular fluorescence intensity of MonoMac- 6 cells. Enhanced cellular uptake was performed by conjugation of new in silico identified drug candidates to OT14 tuftsin derivative.

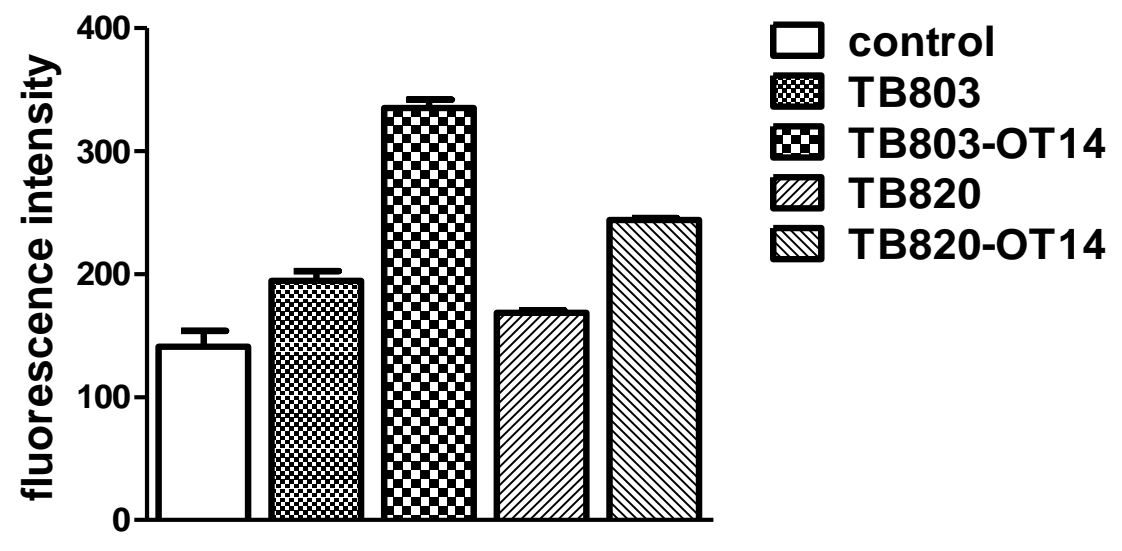

Fig. 6. Cellular uptake of the TB803, TB820 and their OT14 conjugates in $250 \mu \mathrm{M}$ concentration by MonoMac6 human monocytic cells.

\section{Conclusions}

Using in silico docking approach the M. tuberculosis dUTPase enzyme has resulted in a new antimycobacterial compound family (TB8). Considering MIC values and chemical structure, two moieties were chosen from this compound family for conjugation to a new heterotrimer OT14 oligotuftsin carrier. Efficient synthetic pathway was applied to conjugate the TB803 and TB820 compounds to peptidic carriers via oxime linkage. The new antitubercular drug candidates and their peptide conjugates were studied for in vitro activity and membrane affinity.

TB803 and TB820 show little membrane affinity in lipid mono- and bilayer models. The evaluation and comparison of the results of the QCM and AFM measurements can give further information to reveal what happens during the interaction between the lipid bilayer and the candidate. The frequency and the resistance changes indicate that the small molecules interact only slightly with the lipid membrane which is in accordance with their low penetration into lipid 
monolayer. Conjugating the drug candidates to OT14 oligotuftsin changed their behaviour dramatically. Enhanced membrane affinity was found in the monolayer studies that increased further when negatively charged DPPC+DPPG lipid mixture was used as model membrane. This indicates that electrostatic interactions play an important role especially in the presence of cationic peptide sequence in the conjugate. A combination of QCM and AFM studies on SLB model showed the strong interaction of drug-peptide conjugates inducing drastic structural changes in the lipid bilayer.

Bioactivity of the compounds was investigated in vitro. All compounds have outstanding inhibitory effect on the $M$. tuberculosis bacterial culture. For the effective treatment of the tuberculosis it is essential for drug candidates to be able to kill intercellular bacteria. Therefore cellular uptake measurements were also performed. The treatment of MonoMac6 cells with the TB803 and TB820 compounds evoked almost the same intracellular fluorescent intensity as that of the untreated control, which means that the uptake rate of the free drug candidates were limited. In contrast, the mean fluorescent intensity was significantly higher after the incubation with the OT14 conjugates. Coupling the compounds to OT14 peptide has resulted in non cytotoxic conjugates, and the intracellular fluorescent intensity of TB803-OT14 and TB820-OT14 conjugates treated cells was higher than that of TB803 and TB820 treated cells. These results are in good correlation with the outcome of the model membrane studies.

\section{Acknowledgements}

This work was financially supported by Hungarian Research Fund OTKA 104928, 104275, 115431. This project was supported by the János Bolyai Research Scholarship of the Hungarian Academy of Sciences (K. H.) and MTA Postdoctoral Research Program (G. Gy.).

\section{References}

[1] É. Kiss, D. Schnöller, K. Pribranska, K. Hill, Cs. B. Pénzes, H. Kand Sz. Bősze, J. Disper. Sci. Technol., 32 (2011) 1728.

http://dx.doi.org/10.1080/01932691.2011.616128

[2] K. Horváti, B. Bacsa, N. Szabó, S. Dávid, G. Mező, V. Grolmusz, B. Vértessy, F. Hudecz and Sz. Bősze, Bioconjug. Chem., 23 (2012) 900.

http://dx.doi.org/10.1021/bc200221t

[3] G. Mező, A. Kalászi, J. Reményi, Z. Majer, A. Hilbert, O. Láng, L. Kőhidai, K. Barna, D. Gaál and F. Hudecz, Biopolymers, 73 (2004) 645.

http://dx.doi.org/10.1002/bip.20024 
[4] V. A. Najjar, Ann. N.Y. Acad. Sci., 419 (1983) 1.

http://dx.doi.org/10.1111/j.1749-6632.1983.tb37086.x

[5] K. Horváti, G. Mező, N. Szabó, F. Hudecz and Sz. Bősze, J. Pept. Sci., 15 (2009) 385.

http://dx.doi.org/10.1002/psc.1129

[6] N. Caccamo and F. Dieli, Eur. J. Immunol., 46 (2016) 303.

http://dx.doi.org/10.1002/eji.201546225

[7] C. M. Gupta and W. Haq, Methods Enzymol., 391 (2005) 291.

http://dx.doi.org/10.1016/S0076-6879(05)91016-1

[8] M. Fridkin and P. Gottlieb, Mol. Cell Biochem.,41 (1981) 73.

hhtp://www.ncbi.nlm.nih.gov.sci-hub.cc/pubmed/7035869

[9] C. A. Lipinski, F. Lombardo, B. W. Dominy and P. J. Feeney, Adv. Drug Delivery Rev., 46 (2001) 3. http://dx.doi.org/10.1016/S0169-409X(00)00129-0

[10] J. J. Irwin and B. K. Shoichet, J. Chem. Inf. Model., 45 (2005) 177.

http://dx.doi.org/10.1021/ci049714+

[11] J. J. Irwin, T. Sterling, M. M. Mysinger, E. S. Bolstad and R. G. Coleman, J. Chem. Inf. Model., 52 (2012) 1757.

http://dx.doi.org/10.1021/ci3001277

[12] B. Varga, O. Barabás, E. Takács, N. Nagy, P. Nagy and B. G. Vértessy, Biochem. Biophys. Res. Commun., 373 (2008) 8.

http://dx.doi.org/10.1016/j.bbrc.2008.05.130

[13] K. Horváti, B. Bacsa, N. Szabó, K. Fodor, G. Balka, M. Rusvai, É. Kiss, G. Mező, V. Grolmusz, B. Vértessy, F. Hudecz and Sz. Bősze, Tuberculosis (Edinb)., 95 (2015) S207.

http://dx.doi.org/10.1016/j.tube.2015.02.026

[14] H. Zhu, R. Runguang, T. Zhang, C. Hao, P. Zhang, J. Wang and S. Li, J. Nanomater., 2015. http://dx.doi.org/10.1155/2015/908585

[15] C. Hao, Q. Liu, Q. Li, J. Zhang and R. Sun, Russ. J. Phys. Chem. A, 90 (2016) 214.

http://dx.doi.org/10.1134/S0036024415120079

[16] P. J. Gomes, A. M. P. S. Goncalves da Silva, P. Ribeiro, O. N. Oliveira Jr. and M. Raposo, Mat. Sci.

Eng. C, 58 (2016) 576.

http://dx.doi.org/10.1016/j.msec.2015.09.017

[17] H. Yun, Y.-W. Choi, N. J. Kim and D. Sohn, B. Korean. Chem. Soc., 24 (2003) 377.

http://dx.doi.org/10.5012/bkcs.2003.24.3.377

[18] É. Kiss, E. T. Heine, K. Hill, Y.-C. He, N. Keusgen, Cs. B. Pénzes, D. Schnöller, G. Gyulai, A. Mendrek, H. Keul and M. Möller, Macromol. Biosci., 12 (2012) 1181.

http://dx.doi.org/10.1002/mabi.201200078 
[19] I. Plasencia, K. M. W. Keough and J. Perez-Gil, Biochim. Biophys. Acta, 1713 (2005) 118.

http://dx.doi.org/10.1016/j.bbamem.2005.06.002

[20] K. Hill, Cs. B. Pénzes, D. Schnöller, K. Horváti, Sz. Bősze, F. Hudecz, T. Keszthelyi and É. Kiss, Phys. Chem. Chem. Phys., 12 (2010) 11498.

http://dx.doi.org/10.1039/c002737e

[21] Cs. B. Pénzes, D. Schnöller, K. Horváti, Sz. Bősze, G. Mező and É. Kiss, Colloid Surface A, 413 (2012) 142.

http://dx.doi.org/10.1016/j.colsurfa.2012.02.013

[22] G. Chimote and R. Banerjee, Colloid Surface B, 45 (2005) 215.

http://dx.doi.org/10.1016/j.colsurfb.2005.08.014

[23] É. Kiss, G. Gyulai, Cs. B. Pénzes, M. Idei, K. Horváti, B. Bacsa and Sz. Bősze, Colloid Surface A, 458 (2014) 178.

http://dx.doi.org/10.1016/j.colsurfa.2014.05.048

[24] J. Li, R. Sun, C. Hao, G. He, L. Zhang and J. Wang, Biophys. Chem., 205 (2015) 33.

http://dx.doi.org/10.1016/j.bpc.2015.05.008

[25] M. Mahato, R. Sarkar, P. Pal and G. B. Talapatra, Indian J. Phys., 89 (2015) 997.

http://dx.doi.org/10.1007/s12648-015-0674-z

[26] M. Mohai, É. Kiss, A. Tóth, J. Szalma and I. Bertóti, Surf. Interface Anal., 34 (2002) 772.

http://dx.doi.org/10.1002/sia.1408

[27] R. P. Richter, R. Berat and A. R. Brisson, Langmuir, 22 (2006) 3497.

http://dx.doi.org/10.1021/la052687c

[28] I. Möller and S. Seeger, J. Mater. Chem. B, 3 (2015) 6046.

http://dx.doi.org/10.1039/C5TB00437C

[29] R. Horváth, B. Kobzi, H. Keul, É. Kiss and M. Möller, Int. J. Mol. Sci., 14 (2013) 9722.

http://dx.doi.org/10.3390/ijms14059722

[30] F. F. Rossetti, M. Bally, R. Michel, M. Textor and I. Reviakine, Langmuir, 21 (2005) 6443.

http://dx.doi.org/10.1021/la0509100

[31] M. de Planque and J. A. Killian, Mol. Membr. Biol., 20 (2003) 271.

http://dx.doi.org/10.1080/09687680310001605352

[32] A. Kunze, P. Sjövall, B. Kasemo and S. Svedhem, J. Am. Chem. Soc., 131 (2009) 2450. http://dx.doi.org/10.1021/ja809608n

[33] K. F. Wang, R. Nagarajan and T. A. Camesano, Colloid Surface B, 116 (2014) 472.

http://dx.doi.org/10.1016/j.colsurfb.2014.01.036

[34] K. F. Wang, R. Nagarajan, C. M. Mello and T. A. Camesano, J. Phys. Chem. B, 115 (2011) 15228. http://dx.doi.org/10.1021/jp209658y 
[35] G. Sauerbrey, Z. Phys., 155 (1959) 206.

http://dx.doi.org/10.1007/BF01337937

[36] L. Sula, Bull. W. H. O., 29 (1963) 589.

http://www.ncbi.nlm.nih.gov/pubmed/?term=14102036

[37] L. Sula, Bull. W. H. O., 29 (1963) 607.

http://www.ncbi.nlm.nih.gov/pubmed/?term=14102037

[38] K. Horváti, B. Bacsa, É. Kiss, G. Gyulai, K. Fodor, G. Balka, M. Rusvai, E. Szabó, F. Hudecz and Sz. Bősze, Bioconjug. Chem., 25 (2014) 2260.

http://dx.doi.org/10.1021/bc500476x

[39] J. Vinšová, M. Krátký, M. Komlóová, E. Dadapeer, S. Stěpánková and K. Vorčáková, Molecules, 19 (2014) 7152.

http://dx.doi.org/10.3390/molecules19067152

[40] T. F. Slater, B. Sawyer and U. Sträuli, Biochim. Biophys. Acta, 77 (1963) 383.

http:/dx.doi.org/10.1016/0006-3002(63)90513-4

[41] T. Mosmann, J. Immunol. Methods, 65 (1983) 55.

http:/dx.doi.org/10.1016/0022-1759(83)90303-4

[42] Y. Liu, D. A. Peterson, H. Kimura and D. Schubert, J. Neurochem., 69 (1997) 581.

http:/dx.doi.org/10.1046/j.1471-4159.1997.69020581.x

[43] A. Kapus, S. Grinstein, S. Wasan, R. Kandasamy and J. Orlowski, J. Biol. Chem., 269 (1994) 23544. http://www.ncbi.nlm.nih.gov/pubmed/?term=8089122

[44] C. Scheich, Z. Szabadka, B. Vértessy, V. Pütter, V. Grolmusz and M. Schade, PLoS ONE, 6 (2011) e28428.

http://dx.doi.org/10.1371/journal.pone.0028428

[45] D. Schnöller, Cs. B. Pénzes, K. Horváti, Sz. Bősze, F. Hudecz and É. Kiss, Prog. Colloid Polym. Sci. 138 (2011) 131.

http://dx.doi.org/10.1007/978-3-642-19038-4_23

[46] L. Huynh, N. Perrot, V. Beswick, V. Rosilo, P. A. Curmi, A. Sanson and N. Jamin, Langmuir, 30 (2014) 564.

http://dx.doi.org/10.1021/la4043809

[47] P. Dynarowicz-Latka, A. Wnetrzak and K. Maklyla-Juzak, J. Membrane Biol., 248 (2015) 1021.

http://dx.doi.org/10.1007/s00232-015-9814-9

[48] H. Mansour, D.-S. Wang, C.-S. Chen and G. Zografi, Langmuir, 17 (2001) 6622.

http://dx.doi.org/10.1021/la0108454

[49] A. Martin, V. E. Granstaff and G. C. Frye, Anal. Chem., 63 (1991) 2272.

http://dx.doi.org/10.1021/ac00020a015 
[50] K. K. Kanazawa and J. G. Gordon II, Anal. Chem., 57 (1985) 1770.

http://dx.doi.org/10.1021/ac00285a062

[51] K. K. Kanazawa and J. G. Gordon II, Anal. Chim. Acta, 175 (1985) 99.

http://dx.doi.org/10.1016/S0003-2670(00)82721-X

[52] Perspectives in Membrane Biology, S. Estrada-O. and C. Gitler (Eds.), Academic Press, New York, 1974. ISBN: 0-12-243650-4

[53] T. Ramos, Scand J Immunol., 17 (1983) 411.

http://dx.doi.org/10.1111/j.1365-3083.1983.tb00807.x

[54] F. Madani, S. Lindberg, Ü. Langel, S. Futaki and A. Gräslund, J. Biophysics, 2011 (2011) Article ID 414729

http://dx.doi.org/10.1155/2011/414729 